\title{
Catorce canciones en romance como modelos de poemas hebreos del siglo XV
}

\author{
Edwin SEROUSSI * \\ Hebrew University, Jerusalén
}

\begin{abstract}
Alrededor de 1545 aparecen en la imprenta hebrea de Constantinopla dos colecciones sefardíes de poesía hebrea religiosa: el compendio Bacašot ('Súplicas'), del que se conserva un único ejemplar en la biblioteca del Jewish Theological Seminary de Nueva York; y la colección de Šelomó Maźal-Tob, Širim uźmirot vetišbahot ('Canciones, cánticos y alabanzas') ${ }^{1}$. En un primer momento se pensó que estos dos libros significaban un nuevo periodo en la larga historia del piyut ('poesía religiosa') sefardí, que había alcanzado su apogeo en la Edad de Oro judía de los reinos hispanos medievales (siglos XI-XII).
\end{abstract}

Se suponía que el periodo iniciado por esas dos publicaciones orientales representaba una nueva fase que reflejaba en las formas y los contenidos de la nueva poesía hebrea las sensibilidades estéticas y

\footnotetext{
* seroussi@mscc.huji.ac.il

1 Este artículo deriva del proyecto Incipitario sefardí: El antiguo cancionero judeoespañol en fuentes hebreas (siglos XV a XIX), que se realiza gracias a una generosa beca de la Israel Science Foundation (grant núm. 835-01-1), en preparación para su publicación. La asistente principal en este proyecto es Rivka Havassy, cuya contribución a este estudio ha sido de gran valor. Quiero expresar también mi profundo agradecimiento a Paloma Díaz-Mas, por su generosa contribución a este artículo, y a Iacob M. Hassán, Elena Romero y Ángel Sáenz-Badillos, por sus lecturas de una versión preliminar del mismo y por sus beneficiosas recomendaciones.
}

Sefarad 65 (2005) págs. 385-411

(1) CSIC

ISSN 037-0894 
religiosas de la segunda generación de los expulsados de España en el Imperio Otomano. En consecuencia, se consideraron algunos de los fenómenos que allí aparecían como novedades propias del periodo posterior a la expulsión, siendo uno de tales fenómenos el uso de canciones españolas, turcas, árabes y griegas como modelos de composición de los textos hebreos.

La idea de un renacimiento en la poesía religiosa sefardí posterior a la expulsión de la Península Ibérica era consecuencia de la convicción -generalizada en estudios históricos y literarios sobre el judaísmo hispánico- de que el siglo XV había sido un periodo de decadencia. Pero esta tesis ha sido ya rebatida en la última década del siglo XX por Gutwirth (1992) y Scheindlin (1997), entre otros; y también estudiosos de la poesía hebraicoespañola, como Sáenz Badillos (2000), han reconsiderado esta supuesta «decadencia» del siglo XV. Más aún, los descubrimientos relativamente recientes de textos judíos en lengua romance de los siglos XIV y XV permiten afirmar la existencia de una creación literaria judía en lengua vernácula de la que casi no se tienen noticias debido a la escasez de textos que han sobrevivido (Díaz-Mas 1993; 2001).

Queremos exponer aquí dos ideas que apoyan esta necesaria revisión de la percepción del siglo XV como época de decadencia cultural sefardí. Primero, mantenemos que la poesía hebrea en la Península Ibérica siguió viviendo y reflejando los cambios culturales que ocurrieron en el seno de la comunidad judía en el siglo XV. Segundo, podemos demostrar que el uso de canciones en lengua romance -por lo menos en castellano y catalán- como modelos para la composición de poemas en hebreo era una práctica bastante difundida más de un siglo antes de la publicación de las colecciones, antes mencionadas, impresas en Constantinopla.

Nos basamos para ello en una nueva lectura del Ms. Oxford, Bodleiana, Mich. 290 (Neubauer, 1094; JNUL, Institute of Microfilmed Hebrew Manuscripts, F 17701), colección de piyutim que menciona diez (o quizás once) canciones en lengua romance como modelos de poemas en hebreo. Es esta la fuente más rica conocida hasta el momento 
que atestigua el uso de modelos romances para poesías sacras en hebreo anteriores a la expulsión

En su catálogo de los manuscritos hebreos de la Biblioteca Bodleiana, Neubauer (1886-1906) hizo una descripción detallada del manuscrito, incluyendo una lista completa de los piyutim, así como de sus íncipits (cuando los hay) en lengua romance ${ }^{2}$. En el suplemento moderno a este cátalogo el manuscrito se describe como «Rite of North Africa (Algiers?), 15th century» (véase Beit-Arié y May, núm. 1094). Que fue compilado en la segunda mitad del siglo XV lo prueba la eulogia zijijonó librajá ('de bendita memoria') que acompaña el nombre del eximio Šelomó Bonafed, uno de los poetas hebreos más distinguidos de la Zaragoza de principios del siglo XV, quien murió poco después de 1445 .

Por los nombres de los poetas mencionados en el manuscrito, así como por el contenido de los poemas, creemos que su origen es la Corona de Aragón, y más especificamente el círculo de hombres de letras judíos, activo en Zaragoza durante las primeras décadas del siglo XV.

Uno de los poetas de mayor relieve en el manuscrito es hehajam harofé ('el sabio doctor') don Yosé Ginilla o Ginella. A él corresponde la autoría de un ticún (oración nocturna de índole mística) para el 13 del mes hebreo de šebat, formado por cinco piyutim. Podemos identificar a este poeta con Jucé (o Yuçe) Chinillo, cirujano que vivía en Zaragoza a comienzos del siglo XV (véanse: Meyuhas Ginio 1992:142; 2002:161). Don Yosé todavía se encontraba entre los vivos cuando el manuscrito fue compilado.

No somos los primeros en citar esta fuente. Lo hizo ya hace casi setenta años el historiador sefardí Isaac Emmanuel, quien advirtió en

\footnotetext{
2 Usamos el término «íncipit» por su arraigo en la literatura especializada sobre el tema. Sin embargo, muchos de estos «íncipits» en realidad no son inicios, sino palabras claves, tomadas, por ejemplo, de los estribillos, las cuales sirven para identificar la canción en lengua romance cuya melodía se aplica al poema hebreo.
} 
la descripción hecha por Neubauer la mención de nueve íncipits en lengua romance (Emmanuel 1936:199-200). Siguiendo a Emmanuel, Hanoch Avenary recogió esta información en su importantísima lista de íncipits judeoespañoles en fuentes hebreas (Avenary 1971, núms. 36, 46, 74, 94, 101, 123, 134, 137, 149 y 174), y además agregó un íncipit que había pasado inadvertido en la lectura hecha por Emmanuel del catálogo de Neubauer.

Pero aparte de la mera mención del fenómeno del uso de canciones en lengua romance como modelos de poesías en hebreo en este manuscrito, ni Emmanuel ni Avenary se aventuraron a sacar ninguna conclusión de tal hecho. Más aún, creemos que ninguno de los dos estudiosos llegó a ver el manuscrito original y, por lo tanto, interesados solamente en los cantares modelos en romance, no llegaron a reflexionar sobre la relación entre los íncipits y los poemas hebreos a los que se aplicaron.

Nuestra investigación sobre el tema nos llevó a otro manuscrito perteneciente también al mismo círculo de poetas activos en Aragón que el ya citado Ms.1094. Se trata del Ms. de Oxford, Bodleiana, Mich. 155 (Neubauer 1984; JNUL, Institute of Microfilmed Hebrew Manuscripts, F 19146), el cual ha sido considerado por los investigadores como el diwán de Šelomó Bonafed (Schirmann 1997; Sáenz-Badillos 2000; Sáenz-Badillos y Targarona 2002). Se trata en realidad de una compilación de tres fuentes diferentes, escritas en varias etapas durante el siglo XV, probablemente en Provenza (BeitArié y May, núm. 1984).

Como en el Ms. 1094, también en éste encontramos nueva documentación relacionada con don Yosé Ginilla. Los fols. 276b-278b del Ms. 1984, escritos en letra cursiva hebrea provenzal, parecen ser autógrafos del propio Ginilla, y contienen ocho piyutim de este poeta compuestos para diversas ocasiones: bodas, dedicación de un nuevo séfer Torá, etc. Uno de esos poemas hebreos con íncipit también en hebreo está dedicado por Ginilla a su hija Reyna, que en la festividad de $\breve{S} a b u^{\prime}$ 'ot de 1453 donó a la sinagoga un nuevo paño de cobertura 
para un séfer Torá como agradecimiento por haberse recuperado de una enfermedad (compárese con Meyuhas Ginio 2002:162). Otro piyut fue compuesto por Ginilla para la dedicatoria de un séfer Torá en Híjar (sobre los Ginillos en Hijar, véase Meyuhas Ginio 2002:162). De aquí deducimos que Ginilla todavía vivía en aquel año.

En el Ms. 1984 encontramos seis íncipits en lengua romance, tres de los cuales son idénticos a los del Ms. Bodleiana 1094 (uno de ellos incluye el segundo hemistiquio de la canción modelo). Cabe notar que Neubauer no anotó esos íncipits en su catálogo, por lo que esta fuente ha pasado inadvertida entre los estudiosos del tema.

El principal objeto de este estudio es situar en su contexto histórico, literario, musical e ideológico esas canciones modelos en lengua romance. Confrontadas con fuentes primarias de un tema que despierta tanto interés entre los estudiosos de la cultura sefardí, creemos que una atenta lectura de dichos manuscritos puede iluminar varios aspectos oscuros en la historia del acervo poético-musical de los judíos hispánicos en el siglo que precedió a su expulsión de la Península.

ÍNCIPITS DE LOS MSS. OXFORD, BODLEIANA 1094 Y 1984: TRANSCRIPCIÓN, CONCORDANCIAS Y ESTUDIO

A partir de las publicaciones de Avenary sobre los íncipits judeoespañoles, prestigiosos hispanistas han publicado breves observaciones sobre algunos de los poemas en lengua romance mencionados en el Ms. Oxford, Bodleiana 1094. Armistead y Silverman (1981, núm. 38) vieron en el íncipit núm. 5 («Jueves primero de mayo») «el principio de algún romance histórico o noticiero pero, que sepamos, no se puede identificar con ningún poema conservado». Por su parte, Frenk (1960) ya había identificado un íncipit relacionado con el núm. 3 («En toda la Sumontaña»), el cual aparece en otra fuente hebrea más tardía mencionada por Avenary: la mencionada colección de Bacašot de Constantinopla (ca. 1545), aquí formulado «En toda la Tramontaña». Se trata de un villancico titulado El vaquero de Moraña, que 
era todavía recordado por Lope de Vega (véase Frenk 2003, núm. 999 y, más abajo, nuestras detalladas notas).

Hasta hace dos décadas la identificación de los íncipits judeoespañoles en el contexto de la poesía culta o popular peninsular estaba limitada a las pocas fuentes accesibles a los investigadores, como las publicaciones modernas de cancioneros antiguos. Los monumentales trabajos de Dutton (1991) y Frenk (2003), que recogen cientos de manuscritos inéditos hasta entonces, nos permiten tener ahora un panorama más claro de la poesía hispánica de los siglos XV y XVI e identificar con más precisión las fuentes de algunos íncipits judeoespañoles mencionados en manuscritos hebreos de la misma época.

Damos a continuación los íncipits en romance que aparecen en los manuscritos citados en su original aljamiado, junto con nuestras propuestas de lectura y los primeros versos de su correspondiente poema en hebreo. Agregamos a la descripción de los íncipits un estudio detallado de cada uno para luego concluir con una apreciación más general sobre el significado de esta fuente.

1. Cuan v[i]en l'albas (1094, f. 163b)

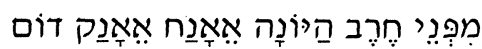

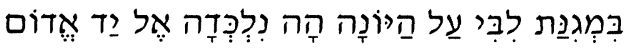

(Abraham Halevy / אברהם הלוי)

No hemos podido identificar este íncipit, que ya había sido mal descifrado por Neubauer en su catálogo y mal interpretado ( Con vigilia levaste») por Avenary (1971). Puede ser leído en catalán o provenzal; en ambos casos recuerda el tema del alba como la ocasión preferida para el encuentro entre los enamorados.

Aparece precediendo a un planto del poeta Abraham Halevy sobre la opresión sufrida por los judíos -representados por la habitual metáfora hebrea medieval de la yoná ('paloma') - a manos de los cristianos -Edom, o sea los edomitas, término de orígen bíblico adju- 
dicado a los cristianos en la literatura hebrea medieval- que quizás se refiera a las matanzas de 1391.

Abraham Halevy era de Gerona y falleció en 1393 (Schirmann 1997:573); eso quiere decir que, si nuestra hipótesis sobre el contexto histórico del poema es acertada, se trataría de un poema escrito en los últimos años de la vida del poeta.

La mención del alba nos recuerda, por supuesto, ese importante tópico de la poesía hispánica estudiado con detalle por Wilson (1977). Aún así no podemos por el momento sugerir ningún poema de alborada específico que corresponda a tal íncipit.

2. די ירושלים / De Yerusaláyim (1094, f. 163b)

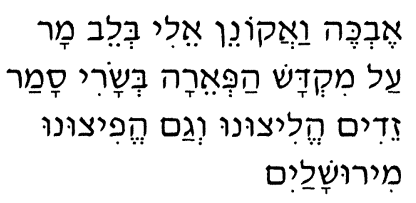

(El'aźar Almajrán / אלעזר אלמכרן)

Se trata del estribillo del famoso planto de cruzada en castellano Ay, Iherusalem, publicado por primera vez por Pescador del Hoyo (1960) y que ha sido objeto de varios estudios desde el pionero de Asensio (1960; véanse también los trabajos fundamentales de Deyermond 1976 y Franchini 1993, y la bibliografía de Franchini 2002).

Que hay que ponerlo en relación con el estribillo de Ay, Iherusalem lo demuestra el hecho de que el íncipit acompaña a un poema hebreo también sobre la destrucción de Jerusalén, escrito por rabí El'aźar Almajrán (o Almabrán), que tiene la misma forma y esquema rítmico que el mencionado planto medieval castellano.

No hemos podido todavía identificar quién fuera ese $\mathrm{El}^{\text {‘azar del }}$ que sólo conocemos este poema, pero nos hemos ocupado ampliamente de este importante descubrimiento en nuestro estudio sobre el tema (Seroussi y Havassy, en prensa). Por lo tanto, mencionaremos 
aquí solamente el hecho de que en el círculo de poetas hebreos del que emana el Ms. Oxford 1094 circulaban poesías en romance antiguo sobre temas cristianos.

En todo caso, la aparición del estribillo del planto de cruzada medieval en este manuscrito de piyutim apunta de nuevo a la relación de algunos de los poemas medievales que publicó Pescador del Hoyo con ambientes culturales judíos o judaizantes, tal como ya han sugerido Hassán (1990; 1992), Cid (1992) y Díaz-Mas (1993; en prensa).

3. אינטודה לה שו מונטאנייה / En_toda la Su-montaña (1094, f. 117a)

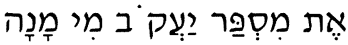

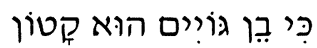

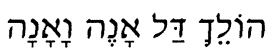

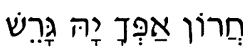

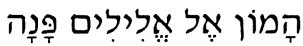

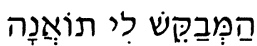

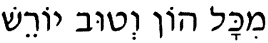

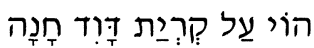

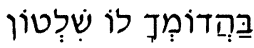

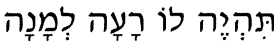

$$
\begin{aligned}
& \text { אֶת מסְפַפר.... }
\end{aligned}
$$

Habíamos señalado más arriba que Frenk identificó con el villancico El vaquero de Moraña una versión de este íncipit, que aparece en la colección Bacašot del siglo XVI. Pero en el caso del manuscrito Oxford el modelo castellano que conocía el autor anónimo del poema hebreo es claramente la famosa serranilla II del Marqués de Santillana (Santillana 1999:108-109), que comienza «En toda la Sumontana / de Trazmos a Veratón / no vi tan gentil serrana».

Rodríguez Moñino ve en este poema el origen de la copla o del villancico sobre este tema difundidos en el siglo XVI (véase Frenk 
2003, vol. I:683-684). Escrita en 1429 en Ágreda, en la frontera con Aragón, el entorno geográfico y la fecha de composición de esta serranilla (Lapesa 1957:318-320) coinciden aproximadamente con el periodo y el lugar de gestación del poema hebreo. Este último es, en efecto, un fiel contrafactum del poema castellano modelo, conservando su esquema métrico, su esquema de rimas $-a b a$ en el estribillo, $c d d c a b a$ en la estrofa, siendo $d$ y $a$ idénticos en el caso del poema hebreo-, así como también el sonido de las rimas, por ejemplo: en v. 1: מי מנה mi maná rima con Sumontaña; en v. 2, קטון es el eco de Veratón, etc.

He aquí una comparación entre el poema hebreo y la primera estrofa de la serranilla del Marqués.

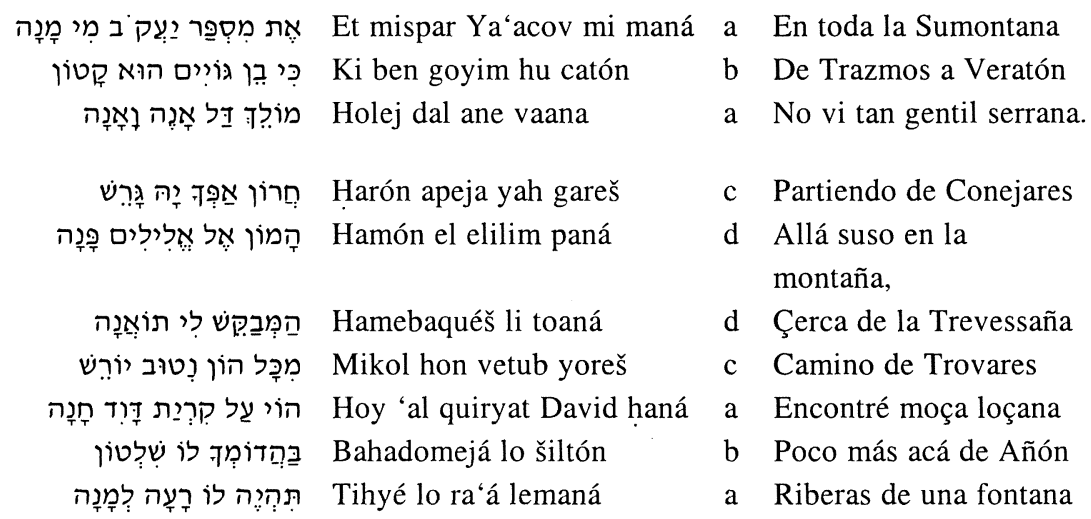

A pesar de esta casi segura relación entre la serranilla del Marqués y el poema hebreo, debemos recordar también la propuesta de Romeu Figueras (1967:48-52) sobre la posible existencia de una versión tradicional, quizás de índole popular, de la que bebiera el Marqués de Santillana. De cualquier forma, sería la de nuestro manuscrito una de las referencias más tempranas a esta famosa serranilla.

Como ya hemos advertido, el mismo poema castellano vuelve a aparecer como íncipit de otro poema hebreo más tardío sobre la caída de Rodas en el año 1525, incluido en el ya mencionado compendio Bacašot (ca. 1545, fol. 13b) y compuesto por Abraham de León. Es, 
pues, un claro ejemplo de la difusión de esta canción entre los judíos españoles también después de la expulsión.

El esquema de rimas del piyut de Abraham de León difiere, sin embargo, del de la serranilla del Marqués, pero se asemeja visiblemente a la forma de villancico que esta serranilla tomó en pliegos sueltos y cancioneros del siglo XVI. Efectivamente, el esquema de rimas del piyut -abba en el estribillo y cdcdceea en la estrofa- es afín al que presentan las versiones del poema español procedentes del siglo XVI que le han servido de modelo ( $a b b a, c d d c a b b a)$.

A continuación comparamos el estribillo y la primera estrofa del piyut con el estribillo y la última estrofa de una versión cabal del villancico que aparece en el Cancionero de Rennert (British Library Add. 10431, fol. 62r; cf. Dutton 1991, núm. 0880; véanse también las fuentes citadas en Romeu Figueras 1967).

\begin{tabular}{|c|c|c|c|}
\hline 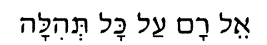 & El ram ‘al kol tehilá & $\mathrm{a}$ & toda la Trasmontana \\
\hline & Yoduja malaj vegalgal & $b$ & Nunca vi cosa mejor \\
\hline & Ki samta me‘ir legal & $\mathrm{b}$ & Quera su esposa de Antón, \\
\hline קִרְיָה בְּצוּרָּ & beŝurá lemapalá & $\mathrm{a}$ & de Morana. \\
\hline 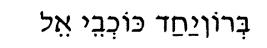 & ebé El & $\mathrm{c}$ & a vemos \\
\hline 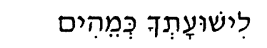 & & d & stra \\
\hline מִיכָאִל וְגַבְריאִל & $\mathrm{Mij}$ & $\mathrm{c}$ & stra \\
\hline גַּם כָּל בְּנְי אֶל הִי & Elohim & $\mathrm{d}$ & nocemos \\
\hline עִם עַמְּך ?יְשְרָאָל & 'Im & $\mathrm{c}$ & \\
\hline בְּלָם יַחַד יְבַנְנוּ & Kulam yahad yeranenu & $\mathrm{e}$ & Sin dexarnos la rendiçión \\
\hline & Ki hijrata et sc & & ativa en tal prisión \\
\hline 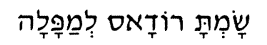 & Samta Rodas lemapalá & & Do libertad no se gana \\
\hline
\end{tabular}

Tan famoso era el íncipit de este poema castellano citado en el compendio Bacašot que el gramático judío italiano Samuel ben Eljanán Archivolti (1515-1611) lo usó en su 'Arugat habósem (Venecia, 1601-1602, fol. 110b) como ejemplo paradigmático en su argumentación contra el uso de modelos foráneos en la composición de poesía hebrea sacra, práctica que por cierto estaba muy en boga en su época. 
4a. גראן טימש אה קים דורה / Gran tems a que'm dura (1094, f. 117b)

4b. גראן טימש אה קים דורה קי שו אינאמוראט / Gran tems a que'm dura que so enamorat (1984, f. 278)

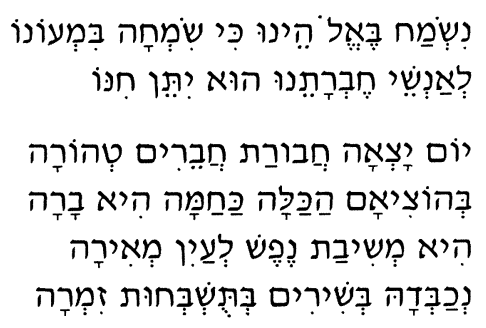

(Don Yosé Ĝinilla / דןו יוסי ג׳ינילייה)

Se trata de un íncipit en catalán: «Hace tiempo que me dura / que estoy enamorado». Acompaña a la composición de don Yosé Ginilla con ocasión de la dedicatoria en Híjar de un nuevo rollo de la Torá por parte de su suegro don Yehudá ben Albalag. El poema utiliza la conocida metáfora de la Torá como novia.

El piyut, como su modelo catalán, está formado por versos dodecasilábicos bimembres. Todos los versos riman en - $r a$, excepto los dos primeros que sirven de encabezamiento y quizás también de estribillo, aunque la versión del poema en el manuscrito no indique ninguna señal de vuelta.

El íncipit en catalán encuentra eco en el primer verso de la primera estrofa del poema hebreo -así haburat suena a «que'm dura» y tehorá a «enamorat»- y no en el par de versos que lo encabezan.

5. גואיביש פרימירו די מאיין / Jueves primero de mayo (1094, f. 161b)

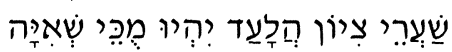

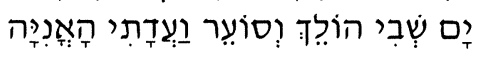

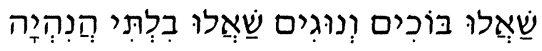

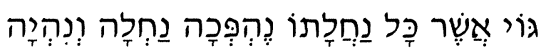

(Šelomó Bonafed / שלמה בונפיד) 
Como ya hemos indicado, Armistead y Silverman (1981) trataron de este íncipit suponiendo que pertencía a algún romance antiguo no identificado. En efecto, el poema hebreo de Šelomó Bonafed se asemeja a un romance con versos de dieciséis sílabas con rima asonante, divididos en dos hemistiquios de ocho sílabas.

El íncipit va precedido por la indicación hebrea letamrur ('melodía de endecha'), lo que nos permite asumir que se trataría más bien de una endecha en forma de romance o de un romance de tema luctuoso. La misma información, pero sin el íncipit en castellano, aparece en la versión del mismo poema hebreo en el Ms. Bodleiana 1984: «letamrur quiná šel lá'az», es decir, '[cantado con la] melodía de una endecha en [lengua] no hebrea' (fol. 54b). La indicación tamrur figura también con el íncipit «Yo vi una cabaña» (véase infra).

6. מי ביאיין טאנטו דישיאדו / Mi bien tanto deseado (1094, f. 117a)

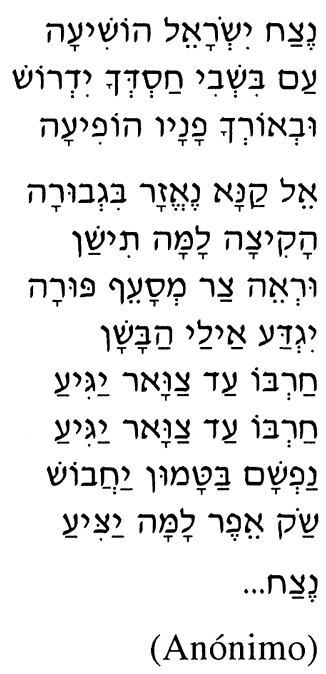

Se trata del íncipit del poema de amor cortesano «Mi bien tanto deseado / çedo vos vean mis oios», atribuido con dudas al Infante Enrique de Aragón (1399-1445). El poema aparece en las siguientes fuentes manuscritas: Cancionero de Herberay (ca. 1465), núm. 186 (British Library Add. 33382); Cancionero de Módena (ca. 1475), núm. 112 (Modena Estense); Cancionero de San Román (ca. 1454), 
núm. 79 (Real Academia de la Historia Madrid). Según Dutton (1991, núm. 0338), las dos primeras fuentes derivan de la Corte de Navarra, partidaria del Infante, y de ahí su dudosa atribución de autoría. La tercera fuente indica como autor al gran poeta Juan de Mena.

El poema ya lo cita el Conde de Mayorga antes de febrero de 1437 (Dutton 1991, núm. 0401). No deja de ser sugerente el que este poema español aparezca mencionado justamente en una fuente hebrea probablemente aragonesa, lo que puede reforzar la tesis de que efectivamente se trata de un poema del Infante.

El poema hebreo anónimo es una habdalá, es decir, una canción para la ceremonia de separación entre el sábado y los días hábiles. El esquema rímico del poema hebreo - $a b a$ (estribillo), $c d c d a b a$ (estrofa)- es muy parecido al del poema Mi bien tan deseado - $a b b$ (estribillo), $c d d c a b b$ (estrofa)-.

\begin{tabular}{|c|c|c|c|}
\hline 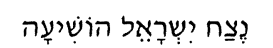 & Néŝah Yisrael hošîa & & Mi bien tanto deseado \\
\hline 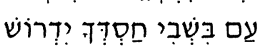 & 'Am bišbí hasdejá yidróš & & Çedo vos vean mis ojos \\
\hline וּבְאוֹרְך פָנָּיו הוֹפִיעָה & Uborejá panav hofí‘a & & Por que çessen mis enojos \\
\hline אִל קַָּּא נְאַזָר בִּגְבוּרָה & El caná neeźar bigburá & & No podriades pensar \\
\hline הָקִיצָה לָָָּה תִישׁן & Haquiŝa lama tišán & & mi desseo \\
\hline וּרְאִה צַר מִסָעִף פּוּרָה & Uré ŝar mésa ‘éf purá & & non vos veo \\
\hline 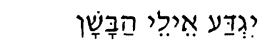 & Yigda‘ elé haBašán & & No $n$ \\
\hline 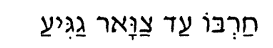 & Harbó 'ad ŝavar yaguía' & & Mas que quitar este cuydado \\
\hline נַפְשָס בַּטּטמוּן & Nafšam batamún yahabóš & 0 & Çedo vos vean mis ojos \\
\hline 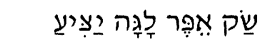 & Sac efer lama yaía‘ & $a$ & Por que çessen mis enojos \\
\hline
\end{tabular}

7a. נו פוקפארטיר ני אטוראר / No puc_partir ni aturar (1094, f. 117a)

7b. נון פוק פארטיר ני אטוראר / Non puc partir ni aturar (1984, f. 277b)

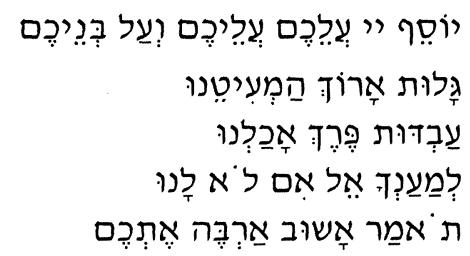

(Don Yosé Ĝinilla / דון יוסי ג׳ינילייה) 
Se trata de un segundo íncipit en catalán («No puedo partir ni quedarme») no identificado, que aparece precediendo a otro poema de don Yosé Ginilla, cuyo apellido se lee en el acróstico del piyut. éste presenta un esquema rímico de zejel con estribillo: $a a$ (estribillo), $b b b a, c c c a$, etc. (estrofas). Podría tener alguna relación con la canción castellana más tardía «No puedo apartarme / de los amores madre», que aparece por primera vez justamente en el Cancionero catalán del Ateneu de Barcelona (véase Dutton 1991, núm. 2790) y más tarde también en el Cancionero musical de Palacio y otras fuentes (Frenk 2003, núms. 247A y 248B). Ese poema castellano tiene la misma forma que el piyut.

8a. נו [גו?] וי אונה קאבאנייה / No [Yo?] vi una cabaña (1094, f. 162a) 8b. ייו וי אונה קאבאנייה / Yo vi una cabaña (1984, f. 55a)

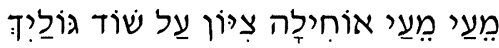

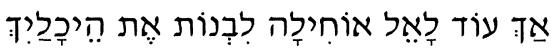

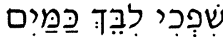

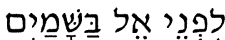

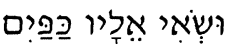

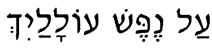

(Šelomó Bonafed / שלמה בונפיד)

Se trata de un íncipit todavía no identificado adaptado a una muwaššah hebrea compuesta por Šelomó Bonafed. Neubauer leyó «No» en el Ms. 1094, pero la primera letra se puede leer también como guímel, o sea «Jo» o «Yo»; por su parte, en el Ms. Bodleiana 1984 (fols. 55a-55b) la primera palabra se lee claramente «Yo».

Se puede leer indistintamente en español o en catalán, como lo sugiere Sáenz-Badillos (2000:354: «Jo vei una cabanya»; véanse también: Sáenz-Badillos y Targarona, 2002:42*; Schirmann 1997:643, nota 45; Bejarano, 1989, I, p. 65, lee: «Yo ví una que venía»). En ambos manuscritos este íncipit está acompañado del término tamrur. 
9. פור מי מאל ווש אמי / Por mi mal vos amé (1094, f. 117b)

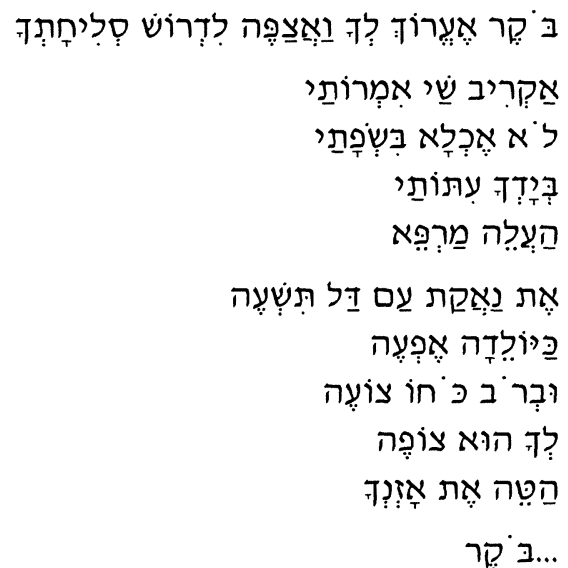

(Anónimo)

9a. פור מי מאל ווש אמי / Por mi mal vos amé (1094, f. 123a)

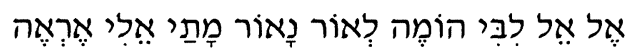

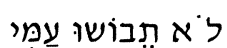

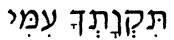

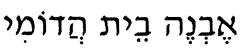

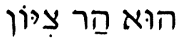

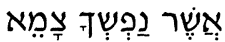

(Anónimo)

Es el único íncipit en el Ms. Oxford que acompaña a más de un poema hebreo, en este caso a dos, ambos anónimos, los cuales están formados mayoritariamente de versos dodecasilábicos bimembres con el mismo esquema de rimas: $a a$ (estribillo), $b b b c a$, dddca, etc. (estrofas).

En los dos poemas el estribillo lo forma un verso más largo (dieciséis sílabas), aunque, al parecer, las cuatro sílabas adicionales pueden responder a una interjección interpolada entre los dos hemistiquios. 
El segundo poema es un contrafactum más claro de la canción castellana. Su primer hemistiquio «El El libí homé» suena como su paralelo en el modelo en lengua romance: «Por mi mal vos amé». Entre los dos hemistiquios del estribillo de este segundo poema se incrustan las palabras leor naor, que podrían corresponder a una interjección, como «amor, amor».

10. שי דיליביראדו טיניש קי אה וואישטרה מאנו מואירה Si deliberado tenés que a vuestra mano muera (1094, f. 117a)

$$
\begin{aligned}
& \text { שִיר שֶׁבַח הוֹדוֹת חַדְּשׁ } \\
& \text { אוֹמְרָה אֶׁמוֹר בְּמוֹרָא }
\end{aligned}
$$

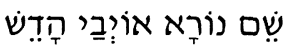

$$
\begin{aligned}
& \text { שֶׁם נוֹרָא נִּרי תָאִיר }
\end{aligned}
$$

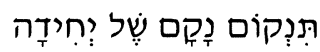

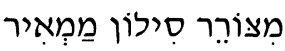

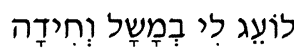

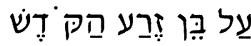

(Anónimo)

Se trata de un poema anónimo del siglo XV (Dutton 1991, núm. 2287), que aparece en el Cancionero de Heberbay y en el Cancionero de Módena. Es de interés señalar que son estas las mismas fuentes en las que aparece el poema «Mi bien tanto deseado» (véase núm. 6 supra). El esquema rímico del poema hebreo - aba (estribillo), $c d c d a b a$ (estrofas)- es casi idéntico al del poema castellano. Casi todo el poema hebreo -también anónimo- resuena claramente castellano, por ejemplo el íncipit: Šir šébah hodot hadéš, omrá emor bemorá equivale a «Si deliberado tenés, que a vuestra mano muera». La tabla siguiente resume la relación entre los poemas en hebreo y en español, según la versión del Cancionero de Heberbay. 


\begin{tabular}{|c|c|c|c|}
\hline שִשיר שֶׁבַח הוֹדוֹת חְָּּש & Šir šébah hodot hadéš & a & Si deliberado teneys \\
\hline אוֹמְרָה אֶמוֹר בְּמוֹרָא & Omerá emor bemorá & & Que por vuestra mano muera \\
\hline שִׁס נוֹרָא אוֹיְבַי הָדִש & Šem norá oibay hadéš & & Señora, no lo tardeys. \\
\hline 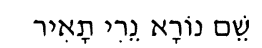 & Šem norá nerí taír & & Señora, si en yo morir \\
\hline תִנְנְוֹם נָקָם שֶל יְחידָה & Tincom nacam šel yehidá & d & Entendeys de ser seruida \\
\hline מִצוֹרִר סִילוֹן מַמְאִיר & Miŝorer silón mamir & & E ved que por vos servir \\
\hline לוֹעֵג לִי בְמָשָל וְחִידָה & Lo'eg li bemašal vehidá & $d$ & Yo quiero perder la vida \\
\hline על בָּן זֶברע הַק דֶּט & 'Al ben źera' hacodeš & & tarme aveis \\
\hline אוֹמְרָה אֶמוֹר בְּמוֹרָא & & & \\
\hline שִׁם נוֹרָא אוֹיְבַי הָדָט & & & me non tardeys \\
\hline
\end{tabular}

11. אונה פ'ראירה [פ'ראידה? Una fraira [?] [feraida?, ferida?] (1094, f. 82a, márgen)

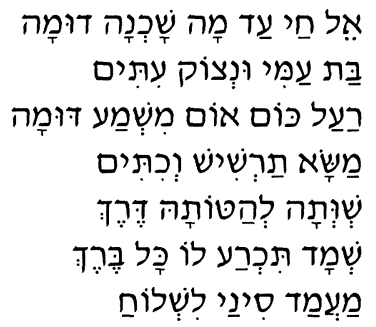

(Abraham Halevy / אברהם הלוי)

Se trata de una nota casi ilegible al márgen del manuscrito. Si nuestra propuesta de lectura es correcta, se podría entender como «una monja». Otras posibles lecturas, como, por ejemplo, «una ferida», me parecen menos plausibles. El poema hebreo, de Abraham Halevy, tiene forma de villancico, con estrofa de siete versos de rima ababccd.

12. נונקה טאן טרישטי פארטידה / Nunca tan triste partida (1984, f. 277a)

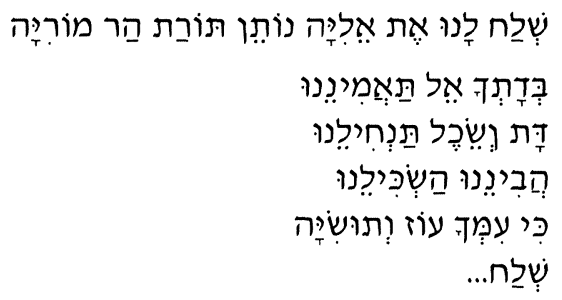

(Don Yosef Ĝinilla / דון יוסף ג׳יניליה) 
Se trata de otro piyut de don Yosé Ginilla de estrofa zejelesca con encabezamiento: $a a$ (estribillo), $b b b a$ (estrofas). Por su contenido se trata posiblemente de otra canción para la ceremonia de habdalá. A pesar de que el tópico de la triste partida abunda en la poesía del siglo XV, no hemos podido identificar ninguna canción española con este preciso íncipit.

13. מיגאליקא אישטא[ב] Mi-galica esta[b]a (1984, f. 277a)

Íncipit alternativo que aparece precediendo al mismo poema hebreo que hemos descrito en núm. 12.

14. [ ] so yo que me[?]sta [ ] mas [י יו קי מיש [?]טה [ ] מאש נונקה לו [1984) nunca lo [ (1984, f. 278b)

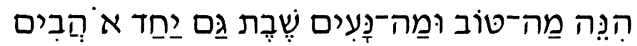

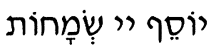

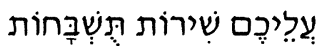

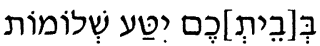

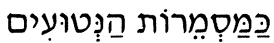

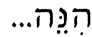

(Don Yosef Giinilla / דון יוסף ג׳יניליה)

Este íncipit, de difícil lectura, aparece precediendo a una canción de boda de estrofa zejelesca, compuesta por don Yosé Ginilla.

\section{CONCLUSIONES}

La canción popular en judeoespañol es hasta el presente uno de los componentes más perdurables y significativos de la cultura sefardí. En varios estudios hemos mostrado cómo buena parte del acervo musicopoético en ladino de tradición oral recogido en encuestas de campo realizadas desde el final del siglo XIX es de relativa nueva creación 
(véanse, por ejemplo, Seroussi 1995 y 1999). Ello no significa negar la antigüedad de la canción judeoespañola, sino afirmar su permanente y activa evolución.

Como este estudio lo demuestra, ya a finales del siglo XIV la canción en lengua romance formaba parte integral de la cultura hispanojudía, por lo menos entre las capas más eruditas. Los datos recogidos en este artículo se suman a los ya conocidos por otras fuentes, como las canciones de boda judías en catalán que publicara Moshe Lazar (1970) y republicara Jaume Riera i Sans (1974), una canción de boda bilingüe hebreo-castellana del siglo XV (Lazar 1999:662-665), o los íncipits castellanos que recoge Yahalom (1988) en su estudio de un manuscrito de quinot ('endechas') del siglo XV.

Sobre lo que los manuscritos de Oxford nos ilustran claramente es que desde finales del siglo XIV -si no antes- poetas hebreos de habla castellana y catalana conocían canciones contemporáneas de diversos géneros y registros: noticieras (incluidos romances), endechas, líricas del repertorio cortesano y otras de índole más popular. Tal conocimiento derivaba seguramente de un contacto estrecho entre judíos y cristianos, por lo menos en las altas esferas sociales, como lo demuestran la proximidad de judíos a una figura como el Marqués de Santillana y el interés que el propio Marqués mostraba por asuntos judíos (véase Girón Negrón 2000).

Podemos precisar también que, siguiendo la práctica medieval hebrea de imitar metros y esquemas de rima de poesías existentes (especialmente en el género de las muwaššahat), los modelos en lengua romance de los manuscritos de Oxford no eran solamente poéticos, sino también musicales. Esto lo muestran las indicaciones de vueltas de estribillos que, para beneficio de los ejecutantes, aparecen en los manuscritos.

Los manuscritos de Oxford son colecciones que, en contraste con manuscritos de poemas hebreos religiosos de siglos anteriores, recogen poemas de varios autores a veces procedentes de diversas zonas de la Península. En nuestro caso encontramos menciones de poemas de los aparentemente catalanes Abraham Halevy y don Yosé Ginilla, de Šelomó 
Bonafed, que también vivía en la Corona de Aragón, y de otros poetas anónimos. Podría ser que este tipo de manuscritos, que, aparte de poemas, incluyen además otros materiales, como epístolas y apuntes circunstanciales, pertenecieran o incluso los hubieran compilado cantores dedicados a la ejecución de poemas en diversas ocasiones sociales, como bodas o reuniones en las sinagogas.

$\mathrm{Al}$ respecto es interesante señalar que, durante esta primera etapa de la historia de la canción sefardí en lengua romance, muchos de sus practicantes eran hombres cultos que tenían acceso a la poesía cortesana contemporánea, como lo demuestra el caso de la serranilla del Marqués de Santillana. Es de advertir también que en los círculos cortesanos aragoneses y catalanes de los siglos XIV y XV, de donde probablemente provienen los materiales tratados en este estudio, actuaban muchos juglares judíos y conversos que podrían haber servido de eslabón entre el mundo poético cortesano y las comunidades judías locales (véanse: Romano 1988; Blasco 1998).

Evidentemente algunos de estos poemas cultos pasaron por un proceso de tradicionalización y eventualmente fueron transmitidos también de forma oral por judíos, hombres y mujeres. Desafortunadamente, casi nada sabemos sobre el cancionero de transmisión puramente oral entre los judíos hispánicos de los siglos XIV y XV, aunque las fuentes hebreas del siglo XVI en adelante sí testimonian su existencia.

Por ahora no podemos precisar si las prácticas de composición poética hebrea reveladas por los manuscritos de Oxford resultaban novedosas en su tiempo o si representan la continuación de técnicas más antiguas, cuyas raíces puedan quizás encontrarse en las jarchas mozárabes de poemas hebreos de los siglos XI y XII. Tampoco podemos precisar si todas las canciones en castellano o en catalán conocidas por los judíos en la Península Ibérica en el siglo XV eran comunes con los repertorios cristianos (como lo demuestran varios íncipits estudiados aquí), o si ya existía en aquella época un cancionero hispanojudío de características particulares. Al menos, por la evidencia de los ejemplos que hemos analizado aquí, da la impresión de que durante el siglo XV los judíos 
compartían los repertorios líricos con sus compatriotas cristianos. Pero sí parece que ya durante el mismo siglo XV existía un repertorio particular de endechas en el repertorio judío lírico peninsular (Gutwirth 1993; Díaz-Mas, en prensa).

El hecho es que, para cuando fueron expulsados de la Península Ibérica, los sefardíes poseían un caudaloso repertorio de canciones en lengua romance de origen culto y también popular, que en las tierras de exilio se perpetuó casi exclusivamente por tradición oral. Los íncipits en castellano de poemas hebreos son, por lo tanto, casi la única documentación escrita que se nos ha conservado sobre la presencia de estas canciones en la sociedad sefardí exiliada.

Con el paso del tiempo, el repertorio peninsular antiguo que los sefardíes llevaron al exilio evolucionó, creando sus propias variantes y acrecentándose, bien con creaciones originales, como lo atestiguan las coplas sefardíes (Romero 1988; 1992), bien con canciones nuevas que llegaban a los sefardíes del Mediterráneo oriental por medio de conversos o por contactos con mercaderes y diplomáticos ibéricos, así como con canciones locales (turcas, griegas, árabes, etc.) reformuladas en ladino.

Debido a las dificultades materiales con las que se enfrentaron los emigrantes sefardíes, han quedado poquísimos ejemplos de íncipits en lengua romance de la primera mitad del siglo XVI, ya que muchas fuentes impresas y manuscritas obviamente se perdieron con los avatares del reasentamiento.

Sin duda, los primeros cancioneros de poesía hebrea religiosa con íncipits en castellano en manuscritos o impresos que aparecen en el Imperio Otomano casi medio siglo después de la expulsión son la directa continuación de prácticas anteriores a aquélla. Hacia el final del siglo XVI y principios del XVII los íncipits de canciones en judeoespañol mencionados en la obra monumental del gran poeta sefardí de Oriente rabí Israel Najara (ca. 1555-1625) revelan la riqueza hasta ese momento no documentada de tal cancionero, especialmente en su registro popular (Seroussi 1990). Este último será eventualmente el estrato dominante del 
cancionero sefardí oral a expensas de un cancionero antiguo más culto que poco a poco fue desapareciendo de la memoria comunitaria.

Poco ha quedado, por lo tanto, de los estratos más antiguos del cancionero lírico ibérico en el cancionero sefardí del presente. A pesar de ello, no puede dejar de asombrarnos cómo han perdurado, en el acervo músico-poético sefardí de tradición oral moderna, ideas, temas y giros lingüísticos derivados de la poesía medieval en lengua romance que conocieron los judíos hispánicos antes de la expulsión.

\section{BIBLIOGRAFÍA}

Armistead, Samuel G. y Joseph H. Silverman. 1981. «El antiguo cancionero sefardí: Citas de romances en himnarios hebreos (siglos XVI-XIX)», Nueva Revista de Filología Hispánica 30/2 (1981) págs. 453-512.

ASENSIO, Eugenio. 1960. « $i$ Ay, Iherusalem! Planto narrativo del siglo XIII», Nueva Revista de Filología Hispánica 14 (1960) págs. 251-270; reimpreso en Poética y realidad en el Cancionero Peninsular de la Edad Media (Madrid 1970) págs. 263-288.

AVENARY, Hanoch. 1971. «Cantos españoles antiguos mencionados en la literatura hebrea», Anuario Musical 25 (1971) págs. 67-79.

BeIT-ARIÉ, Malachi (comp.) y R. A. MAY (ed.). 1994. Catalogue of the Hebrew Manuscripts in the Bodleian Library, Supplement of Addenda and Corrigenda to Vol. I (A. Neubauer's Catalogue) (Oxford 1994).

Bejarano, Ana. 1989. Šelomó Bonafed, poeta y polemista hebreo (s. XIV-XV), Tesis Doctoral (Universidad de Barcelona 1989).

BLASCO, Asunción. 1998. «Jewish and Convert Jongleurs, Minstrels and 'Sonadores' in Saragossa (Fourtheenth and Fifteenth Centuries)», Orbis Musicae 12 (1998) págs. 49-72.

CID, Jesús A. 1992. «Lamentación del alma ante la muerte: Nuevo poema medieval judeo-español», en Estudios de Folklore y Literatura 
dedicados a Mercedes Díaz Roig, eds. Beatriz GaRZA CuARón e Yvette JIMÉNEZ DE BÁEZ (Mexico D.F. 1992) págs. 729-791.

DEYERMOND, Alan. 1978. «Ay Jherusalem, estrofa 22: 'traductio' y tipología», en Estudios ofrecidos a Emilio Alarcos Llorach (Oviedo 1978) vol. I, págs. 263-290.

DíAZ-MAS, Paloma. 1993. «Un género casi perdido de la poesía castellana medieval: La clerecía rabínica», Boletín de la Real Academia Española 73 (1993) págs. 329-346.

—. 2001. «Poesía medieval judía», en Judíos en la literatura española, eds. Iacob M. HASSÁN y Ricardo IZQUIERDO BENITO (Cuenca 2001) págs. 29-56.

- En prensa. «Las endechas sefardíes sobre la destrucción del Templo y sus paralelos cristianos medievales», en The Medieval Roots of Sephardic Poetry, Papers of the Medieval Hispanic Research Seminar 22 (London).

DutTon, Bryan. 1991. El cancionero del siglo XV (c. 1360-1520), 7 vols. (Universidad de Salamanca 1991).

Emmanuel, I. S. 1936. Historie des Israélites de Salonique, vol. I (Paris 1936).

FRANCHINI, Enzo. 1993. «Ay Iherusalem: una canción de cruzada castellana?», en Actas do IV Congresso da Associaçao Hispanica de Literatura Medieval (Lisboa 1993) vol. II, págs. 343-348.

—. 2002. «Ah Iherusalem», en Diccionario filológico de literatura medieval española, eds. Carlos Alvar y José Manuel LuCía MEgÍAS (Madrid 2002) págs. 202-204.

FRENK, Margit. 1960. «El antiguo cancionero sefardí», Nueva Revista de Filología Hispánica 14 (1960) págs. 312-318.

—. 2003. Nuevo corpus de la antigua lírica popular hispánica (Siglos XV a XVII) (México - Madrid 2003).

GIRÓN NEGRÓN, Luis Manuel. 2000. «Huellas hebraicas en la poesía del Marqués de Santillana», en Encuentros and Desencuentros: Spanish 
Jewish Cultural Interaction throughout History, eds. Carlos CARRETE PARRONDO et al. (Tel Aviv 2000) págs. 161-212.

GUTWIRTH, Eleazar. 1992. «Towards expulsion 1391-1492», en Spain and the Jews: The Sephardi Experience 1492 and After, ed. Elie KEDOURIE (London 1992) págs. 51-73.

—. 1993. «A Judeo-Spanish endecha from the Cairo Genizah», Mediterranean Language Review 6-7 (1993) págs. 113-120.

HASSÁN, Iacob M. 1990. «Judaísmo en dos de los tres 'nuevos' poemas medievales», (Ponencia no publicada) en Seminario Internacional de las Tres Culturas, Medina del Campo, 5-9 feb. 1990.

—. 1992. «Adóte Adán / ¿Dónde estás Adán? en las literaturas judeoespañola e hispanojudía», en Hispanic Medieval Studies in Honor of S. G. Armistead, eds. E. Michael Gerli y Harvey L. SHARrer (Madison 1992) págs. 163-172.

LAZAR, Moshe. 1970. «Catalan-Provençal Wedding Songs $\left(14^{\text {th }}-15^{\text {th }}\right.$ centuries)», en Hayyim (Jefim) Schirmann Jubilee Volume, eds. Shraga ABRAMSON y Aaron MIRSKY (Jerusalem 1970) págs. 159-177.

—. 1999. Sefarad in My Heart: A Ladino Reader (Lancaster, CA 1999).

LAPESA, Rafael. 1957. «Sobre la fecha y el sentido de la Serranilla II», en La obra literaria del Marqués de Santillana (Madrid 1957).

Meyuhas Ginio, Alisa. 1992. «La familia Ginio (Chinillo, Chiniello, Tchenio, Tchnyo, Ginio): de Aragón a Salónica y Jerusalén», Miscelánea de Estudios Árabes y Hebraicos 41/2 (1992) págs. 137-149.

—. 2002. «The Ginios of Salonika and wine production in Jerusalem», en The Mediterranean and the Jews, eds. Elliott HoROwITZ y Moshe ORFALI (Ramat-Gan 2002) págs. 157-174.

Neubauer, A. 1886-1906. Catalogue of the Hebrew manuscripts in the Bodleian Library and in the College Libraries of Oxford (Oxford 1886-1906). 
PESCADOR DEL Hoyo, María del Carmen. 1960. «Tres nuevos poemas medievales», Nueva Revista de Filología Hispánica 14 (1960) págs. 242-250.

RIERA I SANS, Jaume. 1974. Cants de noces dels jueus catalans (Barcelona 1974).

Romano, David. 1988. «Mims, Joglars i Ministrers Jueus a la Corona d'Arago (1352-1400)», en Studia in honorem Prof. M. de Riquer (Barcelona 1988) vol. III, págs. 133-149.

Romero, Elena. 1988. Coplas sefardíes. Primera selección (Córdoba 1988).

—. 1992. La creación literaria en lengua sefardí. Cap. IV: Las coplas (págs. 141-176) (Madrid 1992).

Romero, Elena, Iacob M. HASSÁn y Leonor CARRACEDO. 1992. Bibliografía analítica de ediciones de coplas sefardies (Madrid 1992).

Romeu Figueras, José. 1967. «'El Toro’, ensalada poeticomusical inédita: Estudio sobre temas taurinos y vaqueros de la lírica tradicional», Anuario Musical 20 (1967) págs. 25-58.

SÁENZ BADILlos, Ángel. 2000. «Šelomoh Bonafed at the Crossroad of Hebrew and Romance Cultures», en Encuentros and Desencuentros: Spanish Jewish Cultural Interaction throughout History, eds. Carlos CARRETE PARRONDO et al. (Tel Aviv 2000) págs. 343-379.

SÁEnz-Badillos, Ángel y Judit TARgarona. 2002. «Strophic Poems in the diwān of Šelomoh Bonafed», en Studies in Hebrew Literature of the Middle Ages and Renaissance in Honor of Professor Yona David (=Te'uda 19), eds. Tova Rosen y Avner HoltZMAN (Tel Aviv 2002) págs. 21-46.

Santillana, Marqués de. 1999. Poesía lírica, ed. Miguel Ángel Pérez PRIEGO (Madrid 1999).

SCHEINDLIN, Raymond P. 1997. «Secular Hebrew Poetry in FifteenthCentury Spain», en Crisis and Creativity in the Sephardic World 1391-1648, ed. Benjamin R. GAMPEL (New York 1997) págs. 25-37. 
SCHIRmann, Hayyim. 1956-1960. The Hebrew Poetry in Spain and Provence, 4 vols. (Jerusalem - Tel Aviv 1956-1960) (En hebreo).

- 1997. The History of Hebrew Poetry in Christian Spain and Southern France, ed. Ezra FLEISCHER (Jerusalem 1997) (En hebreo).

SEROUSSI, Edwin. 1990. «Rabí Israel Najara: me'aŝeb źimrat hacodeš aharé haguerúš», Assufot 4 (1990) págs. 285-310.

1995. «Reconstructing Sephardi Music in the 20th Century: Isaac Levy and his Chants judeo-espagnols», The World of Music 37/1 (1995) (Jewish Musical Culture - Past and Present) págs. 39-58.

—. 1999. «The Music of the Folksong in Ladino», Pe'amim 77 (1999) págs. 5-19 (En hebreo).

SEROUSSI, Edwin y Rivka HAVASSY. En prensa. «Horbán Yerušaláyim belahan ehad: quiná 'ibrit umacbilatá hanoŝrit», en Leot ulzicarón. Studies in Hebrew Poetry and Jewish Culture in Memory of Aaron Mirsky, eds. Efraim HAZAN y Yosef YAHALOM (Ramat Gan).

WILSON, Edward M. 1977. «Albas y alboradas en la Península», en Entre las jarchas y Cernuda: constantes y variables en la poesía española (Barcelona 1977) págs. 55-105.

YAHALOM, Yosef. 1988. «Poetry as an Expression of Spiritual Reality in the Late Sephardic Piyyut», en Exile and Diaspora. Studies in the History of the Jewish People Presented to Professor Haim Beinart on the Occasion of His Seventieth Birthday, eds. Aaron MIRSKY et al. (Jerusalem 1988) págs. 337-348 (En hebreo). 


\section{RESUMEN}

Por falta de documentación, los comienzos de la lírica judeoespañola en la Península han quedado siempre en la oscuridad. Gracias a dos colecciones manuscritas de poemas hebreos religiosos (piyutim) de la biblioteca Bodleiana de Oxford, se vislumbran ahora algunos de los procesos de formación del cancionero lírico hispanojudío anterior a la expulsión de los judíos de España y Portugal. Mediante atentas lecturas de los primeros versos (íncipits) de poemas en castellano y catalán que aparecen como indicaciones melódicas de piyutim en ambos manuscritos, se pueden entrever algunos aspectos de la lírica en lenguas romances que conocían los poetas y cantores judíos antes de 1492.

PALABRAS ClAVE: piyut, judeo-español, música, poesía.

\section{SUMMARY}

The beginnings of the Judeo-Spanish lyric in the Iberian Peninsula have so far remained in the dark due to the lack of tangible documentation. On the basis of two manuscript collections of Hebrew sacred songs (piyutim) from the Bodleian Library in Oxford, it is possible to illuminate some of the formative processes of the Sephardic lyric song prior to the expulsion of the Jews from Spain and Portugal. Careful readings of the first verses of poems in Castilian and Catalan appearing in these manuscripts as melodic codes for the singing of piyutim show some aspects of the lyric repertoire in romance languages known by Jewish poets and singers before 1492 .

KEYWORDS: piyut, Judeo-Spanish, music, poetry. 